\title{
Safety and influence of a novel extract of fenugreek on healthy young women: a randomized, double-blinded, placebo- controlled study
}

\author{
Aman Khanna', Jestin Thomas², Febi John ${ }^{3}$, Balu Maliakel ${ }^{3}$ and I. M. Krishnakumar ${ }^{3 *}$
}

\begin{abstract}
Background: Fenugreek (Trigonella foenum-graecum) seed is a popular kitchen spice and medicinal herb with wide applications in Indian folklore. Earlier studies have shown that the hydro-ethanolic extracts of fenugreek are efficient in the management of a number of hormone related disorders in women, including post and peri-menopausal discomforts, sexual dysfunctions, lactation and even in amenorrhea. However, systematic informations on their safety and influence on hormonal balance are limited.

Results: Forty-eight healthy menstruating women aged 20 to 48 were randomized either to FHE $(n=24)$ or placebo $(n=24)$ and supplemented with $250 \mathrm{mg} \times 2 /$ day for 42 days. FHE did not produce any side effects or adverse events. It offered significant $(P<0.05)$ beneficial effects to sexual problems $(41.6 \%)$ and irritability $(40 \%)$ among the participants who had higher sexual dysfunctions scores $(>1)$ when monitored by the validated Menopausal Rating Scale (MRS) scale. Further, hormone analysis indicated an enhancement in estradiol $(P=0.040)$, free testosterone $(P=$ 0.025), and total testosterone $(P=0.012)$ in FHE group in comparison to placebo. There were no significant changes in progesterone $(P=0.174)$ and FSH $(P=0.879)$ upon FHE supplementation. The hematological and biochemical safety parameters were also at par with the safety of the extract.
\end{abstract}

Conclusion: Thus, the supplementation of FHE may be considered as a natural alternative for sexual issues in women. Trial registration: CTRI/2018/09/015614 dated 05/09/2018.

Keywords: Fenugreek, Irritability, Menopausal rating scale, Sexual problems, Trigonella foenum-graecum, Women

\section{Introduction}

The reproductive cycle is regulated by the hormones of the hypothalamic-pituitary-gonadal (HPG) axis; mainly the estradiol, progesterone, testosterone, follicle stimulating hormone (FSH), and luteinizing hormone ( $\mathrm{LH})$ [1]. Puberty starts with the rise in LH and estradiol secretions followed by the first menstruation [2]. In the reproductive years, cyclic rise of estrogen and progesterone occurs. While increase in estrogen and progesterone

\footnotetext{
* Correspondence: krishnakumar.im@akay-group.com

${ }^{3}$ R\&D Center , Akay Natural Ingredients Ltd., Cochin, India

Full list of author information is available at the end of the article
}

promoted endometrial proliferation and ovulation, the decreased level leads to endometrial mucosal degeneration (i.e., menstruation) [3]. Estradiol and progesterone levels start declining with the perimenopausal stage and return to pre-adolescent levels by the menopause, which usually occur between the age of 45 and 55 [3]. LH and FSH increase in the absence of ovarian estrogenic feedback [2]. Typical variations in the hormone levels during the life cycle of a woman can be depicted as Fig. 1 [4].

The constant variations in the hormonal levels normally cause a number of physiological and psychological changes in a woman's life. During the menstrual phase, woman may experience mood swings and Dysmenorrhea,

\section{Springer Open}

(0) The Author(s). 2021 Open Access This article is licensed under a Creative Commons Attribution 4.0 International License, which permits use, sharing, adaptation, distribution and reproduction in any medium or format, as long as you give appropriate credit to the original author(s) and the source, provide a link to the Creative Commons licence, and indicate if changes were made. The images or other third party material in this article are included in the article's Creative Commons licence, unless indicated otherwise in a credit line to the material. If material is not included in the article's Creative Commons licence and your intended use is not permitted by statutory regulation or exceeds the permitted use, you will need to obtain permission directly from the copyright holder. To view a copy of this licence, visit http://creativecommons.org/licenses/by/4.0/. 


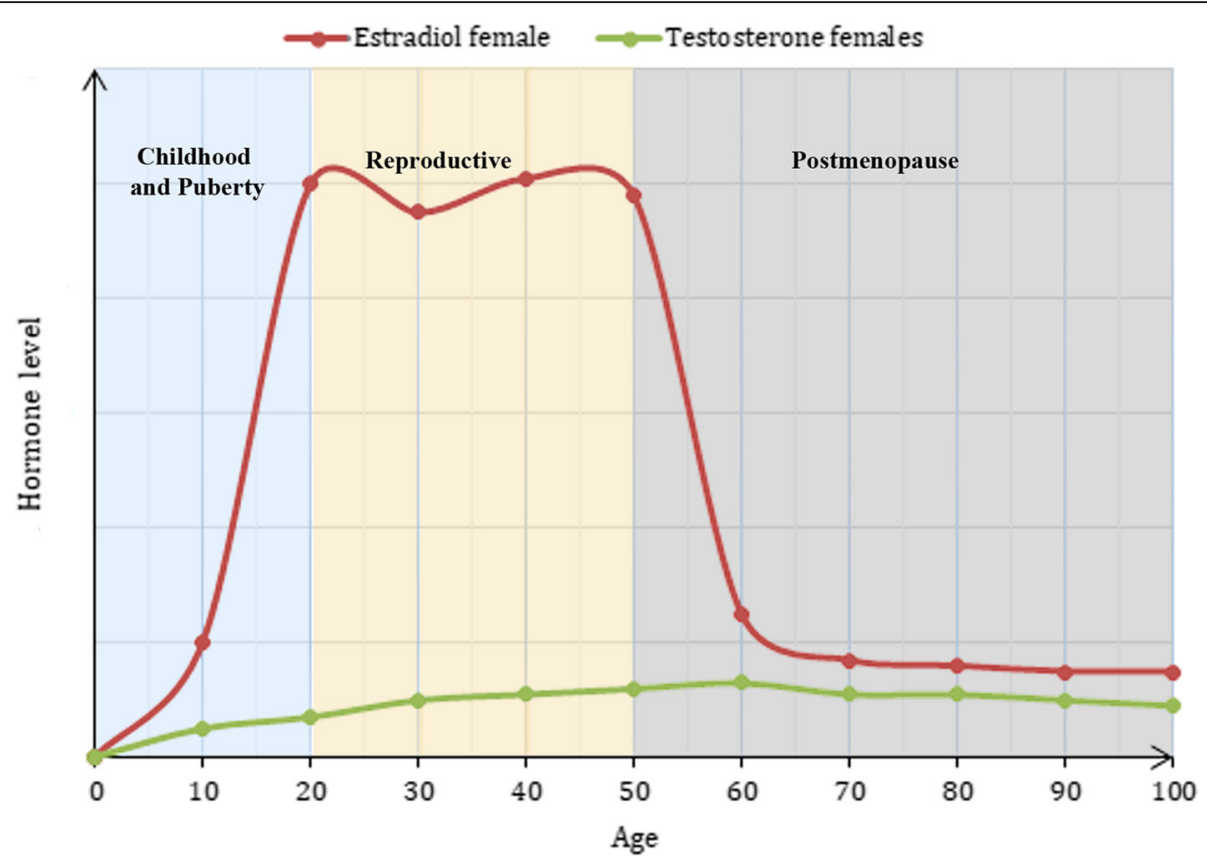

Fig. 1 Variations in hormone levels during the lifetime of women

a severe lower abdominal pain of cramping nature accompanied by vomiting, headache, back pain, diarrhoea and fatigue [5]. Prostaglandins produced by the linings of the uterus have been identified as one of the reasons for the pain since it is known to cause abnormal contractile activity leading to ischemia and hypoxia of the uterus and hence increased sensitivity of the nerve endings [6]. Nonsteroid anti-inflammatory drugs (NSAIDs) are recognized as the first-line treatment in dysmenorrhea [7], though 25 to $30 \%$ failure normally reported [8]. At the menopausal phase, women experience physiologic deterioration of hypothalamic-pituitary-ovarian axis function resulting in hormonal imbalance and a variety of symptoms such as hot flushes, sweating, sleep disturbance, mood swings, depression, cognitive decline, vaginal dryness and sexual dysfunction occur with a significant impact on their quality of life $[9,10]$.

Several herbal remedies have been reported for alleviating various issues associated with various stages of life of a woman, primarily due to the hormonal variations [11]. Fenugreek (Trigonella foenum-graecum) is a popular kitchen spice and medicinal herb that has been shown to possess many useful properties against various physiological issues of women. Fenugreek seeds have been reported to alleviate dysmenorrhea associated with menstruation [12]; supports breast size due to the mastogenic effect [13]; promotes healthy sexual life and mood with a significant impact on libido and vitality among young women [14]; helps to reduce inflammation and body pain associated with child birth [12]; helps the contraction of uterus after delivery and is a galactogogue [15]. In the case of menopausal women, it has been shown to ameliorate various menopausal discomforts related to vasomotor, urogenetic, psychological issues $[16,17]$. Despite all the benefits, human safety studies especially looking at the hormonal safety of fenugreek and its extracts are limited.

Recently, a hydro-ethanolic extract of fenugreek seeds (FHE; Patented and registered as FenuSMART ${ }^{\circ}$ ) containing protodioscin and trigonelline in a 3:1 ratio with around $10 \%$ of protodioscin was reported to alleviate both post and peri-menopausal discomforts when supplemented at 250 $\mathrm{mg} \times 2 /$ day for 42 days $[16,17]$. These studies also have revealed a significant hormonal change (estradiol, progesterone, and testosterone) towards attaining a normal balanced hormone levels among menopausal women [16, 17]. FHE was shown to be tolerated upon supplementation at 500 $\mathrm{mg} \times 2 /$ day for 90 days on 88 postmenopausal women, without significant side effects or adverse events [18]. Therefore, we hypothesised that FHE would also be safe on healthy menstruating women since none of the early studies have shown uncontrolled variations in the reproductive hormones when supplemented to post and peri-menopausal women. Thus, the objective of the present study was to investigate the safety and influence of FHE on the hormone levels of young women at $250 \mathrm{mg} \times 2$ /day for 42 days.

\section{Materials and methods}

\section{Recruitment of study participants}

A total of 48 healthy menstruating women with regular menstrual cycles of 28-34 days and aged 20 to 48 years 
were enrolled for the study. Study participants were identified and recruited from those who accompanied the patients at the outpatient's section of M/s Aman Hospital and Research Centre, Gujarat, India. The study was organized and conducted (generated the random allocation sequence, enrolled and assigned participants to intervention) under the supervision of a qualified Gynaecologist and Nutritionist with the help of a clinical research organization. Participants with MRS (Menopause Rating Scale) score greater than one for either sexual problem or irritability were selected for the study. Detailed inclusion and exclusion criteria are listed in Table 1. A medical screening comprising anthropometric measurements was conducted with all participants.

\section{Intervention}

The proprietary hydro-ethanolic extract of fenugreek seeds (FHE) having a 3:1 $(\mathrm{w} / \mathrm{w})$ protodioscin to trigonelline (Patented \& Registered as 'FenuSMART ${ }^{\text {) }}$ manufactured in their good manufacturing procedure (GMP)-certified plant was obtained from Akay Natural Ingredients, Cochin, India

Table 1 Inclusion and exclusion criteria

Inclusion criteria
1. Age $20-48$ years (both inclusive).
2. Participants having BMI $\leq 30$.
3. Participants with normal blood pressure and fasting blood glucose.
4. Participants understand the study procedures and provides signed
informed consent to participate in the study.
Exclusion criteria

\section{Exclusion criteria}

1. History of cerebrovascular disease, heart attack, or angina at any time or on anti-coagulant or anti-platelet drugs on a daily basis for any conditions.

2. Any previous hormonal treatment or treatment with fenugreek derived products in the previous 12 months.

3. Participants with abnormal ECG, biochemical or hematological values.

4. Any history of using estrogen or progestin containing products in the past 6 months of recruitment.

5. History of breast, endometrial, other gynecological cancer at any period of life or other cancer within the last 5 years.

6. Experiencing depression and/or receiving medication for such illness or disorders, receiving statins or other drugs known to impact on steroid hormone levels.

7. Participants, who are smokers, tobacco or alcohol user.

8. Participated in a clinical study with an investigational drug or biologic within the last 30 days.

9. Use of any recreational drugs (cocaine, amphetamine, barbiturates, benzodiazepines, cannabinoids and morphine)

10. History of clinically significant illness or any other medical disorder that may interfere with treatment, assessment or compliance with the protocol.

11. Any condition that in opinion of the Investigator, does not justify the participants participation in the study. along with a detailed certificate of analysis. High performance liquid chromatography (HPLC) analysis reported that FHE consist of protodioscin (10.3\%), trigonelline (3.1\%), 4hydroxyisoleucine $(2.8 \%)$. Food grade microcrystalline cellulose was employed as the placebo. The quality requirements, mainly related to safety such as microbial content, mycotoxins, heavy metals and pesticides for both FHE and placebo were analysed and certified by an accredited laboratory following the guidelines US pharmacopeia for dietary supplements [19]. FHE and placebo were identically packed into hard-shell, two-piece gelatin capsules, each containing $250 \mathrm{mg}$ of FHE or placebo. The lethal dose $\left(\mathrm{LD}_{50}\right)$, acute (14 days) and repeated dose subchronic (90 days) toxicity of FHE have already been assessed [20].

\section{Study design}

The present study was designed and conducted in a randomized, double-blinded, placebo-controlled and parallel group design. The study was in accordance with the clinical research guidelines of Government of India following the protocol evaluated and was registered in the clinical trial registry of India at http:/ctri.nic.in (CTRI/ 2018/09/015614 dated 05/09/2018).

The details of the experimental procedures including nature and risk were informed to all participants and their written informed consent were obtained before the study. A total of 48 menstruating women were selected by purposive sampling. Baseline sociodemographic variables such as age, race, civil status, marital status, and education were also noted. Participants were randomized to two intervention arms to receive either FHE $(n=24)$ or placebo $(n=24)$. Capsules containing $250 \mathrm{mg}$ of either FHE or placebo were added to sequentially numbered airtight containers and provided on visit 1 (day 0 ). The participants were instructed to take two capsules per day $(250 \mathrm{mg} \times 2)$ (one after breakfast and other after dinner) for 42 days.

A Consolidated Standards of Reporting Trials (CONSORT) flow diagram of the study is shown in Fig. 2a. The participants were monitored through regular telephonic follow-ups and short message services on a weekly basis, through which the daily drug administrations and the details of side effects or discomforts (if any), were enquired. Details of the analyses performed during each visits of the study period were as shown in Fig. 2b.

\section{Randomization and blinding}

Participants were randomly assigned into two groups using the random allocation sequence. The contract research organization staff who was not involved in the screening of participants handled the randomization sequence schedule. The study coordinator who maintained the allocation sequence was updated with the treatment 


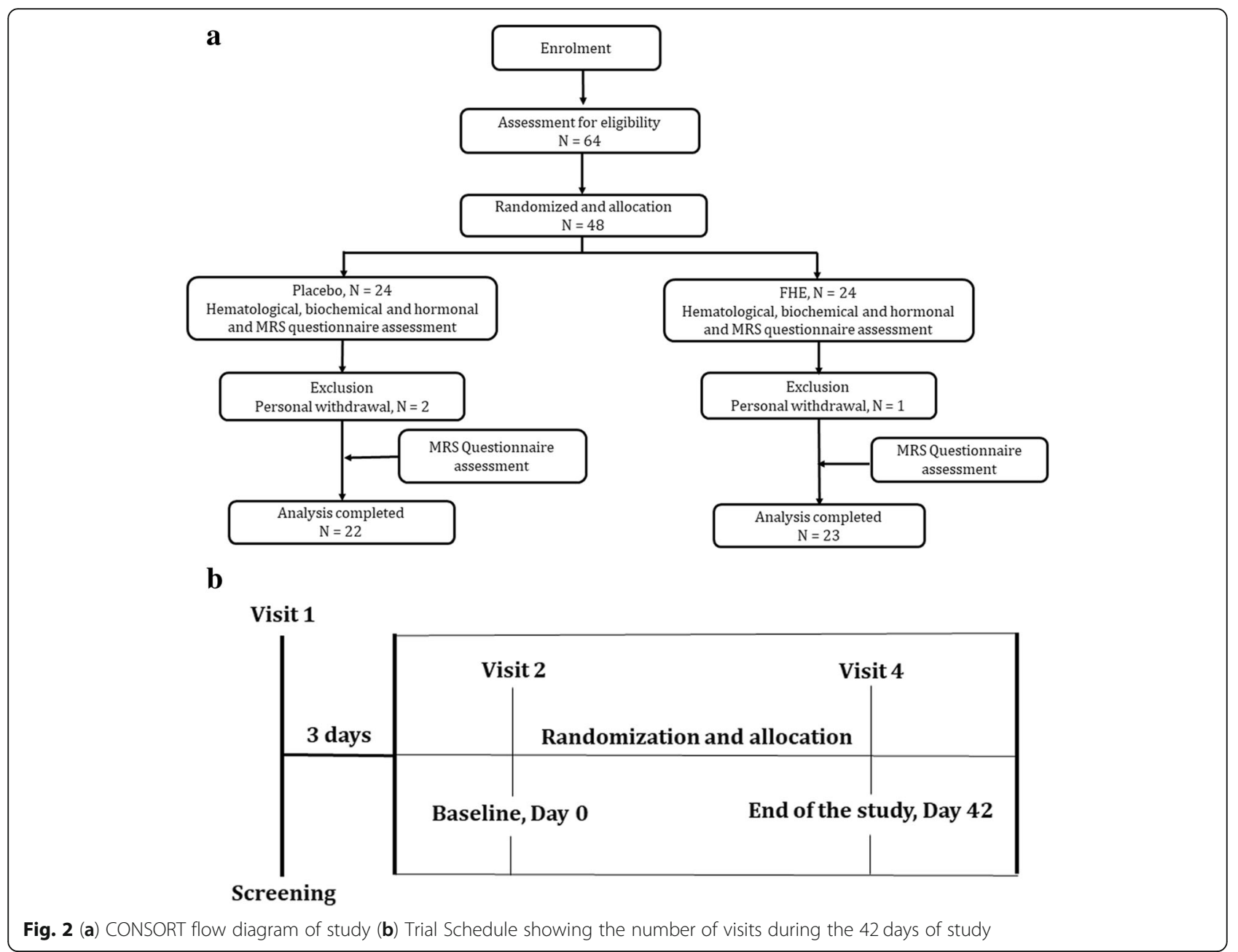

assignment, while the participants and the investigator were blinded to the intervention group.

\section{Outcome measures}

The primary outcome included the efficacy evaluation of supplementation of FHE on sexual problems and irritability as measured by menopause rating scale (MRS) questionnaire on day 0 and day 42. MRS is a healthrelated quality of life monitoring scale developed to measure the severity of menopausal symptoms, including sexual problems and irritability. The questionnaire consists of 11 items, self-completed by the participants at baseline (day 0) and end of study (day 42). The symptoms are classified as somatic (questions 1 to 3 and 11), psychological (questions 4 to 7 ) and urogenital factor (questions 8 to 10). The severity of complaints of each item is described on a 5-point rating scale (score of zero-no complaint and 4-very severe symptom). The composite scores for each of the dimensions (sub-scales) are based on adding up the scores of the items of the respective dimensions and the total score is the sum of the dimension scores [21].

The secondary outcome included the safety and influence of FHE on hormonal balance and comparing it with placebo. Both baseline (Day 0) and end of study (day 42) blood samples were collected by vein puncture and taken into EDTA/non-EDTA vials for hematological and biochemical parameters assay. Serum was separated by centrifugation at $6000 \mathrm{rpm}$ at $4{ }^{\circ} \mathrm{C}$ for $10 \mathrm{~min}$ and stored at $80^{\circ} \mathrm{C}$ for further analysis. The hormones were analysed in serum samples using ELISA kit methods. Human estradiol ELISA kit (Biocompare, USA), progesterone ELISA (Cayman Chemicals, USA), follicle stimulating hormone (FSH) (Abcam, UK), free and total testosterone ELISA kits (Abcam, UK) were employed for analysis. The haematological parameters were assessed using an autoanalyzer (Meril Biochemistry analyzer, Eris diagnostics, and Instruments, India) and biochemical parameters such as serum glutamate oxaloacetate transaminase (SGOT), serum glutamate pyruvate transaminase (SGPT), lipid profiling (total cholesterol, HDL cholesterol, LDL cholesterol, 
VLDL cholesterol and triglycerides), serum creatinine and fasting blood sugar (FBS) were analysed with assay kits provided by M/s Agappe Diagnostics Pvt. Ltd. Bangalore, India.

\section{Statistical evaluation}

The primary efficacy evaluation included the MRS questionnaire based assessment scores corresponding to each of the discomforts at baseline and end of study (day 42). Secondary outcomes including hormonal markers and routine haematological and biochemical markers of safety were assessed at baseline and end of the study period (day 42).

Statistical analyses were carried out using the statistical Package (SPSS Inc. Chicago, IL, USA) version 25.0. Independent $t$-test was used for group comparison (FHE group verses control group) of demographic baseline characteristics and MRS scores. For evaluating the potential changes in hormone levels, biochemical and hematological parameters between placebo and FHE supplemented groups, a $2 \times 2$ repeated measures (RM) analysis of variance were performed with Bonferroni post hoc corrections. The results were presented as mean \pm SD and $P \leq 0.05$ was considered significant.

\section{Results}

\section{Study participants}

Out of the forty-eight participants enrolled, 44 participants successfully completed the study. Three participants were (two from placebo and one from FHE group) withdrawn from the study due to personal reasons. Twenty-two participants in placebo and 23 participants in FHE completed the study as depicted in the cohort diagram in Fig. $2 \mathrm{a} \& \mathrm{~b}$.

\section{Baseline characteristics}

The baseline demographic characteristics measured were statistically insignificant $(P>0.05)$. The participant's sociodemographic variables are presented in Table 2 . The mean age of study participants was $42.85 \pm 4.2$ and $41.10 \pm 3.7$ years, respectively for placebo and FHE groups. The mean baseline body weight of placebo and FHE were $62.3 \pm 4.2$ and $64.8 \pm 4.5$ respectively, baseline BMI in placebo was $23.7 \pm 1.5$, and that in FHE was $24.2 \pm 1.85$. The total, somatic, psychological and urogenital baseline scores as per MRS were $2.26 \pm 1.28$, $0.47 \pm 0.73,0.87 \pm 0.81,0.91 \pm 0.84$ in FHE group and $2.27 \pm 1.27,0.45 \pm 0.59,0.86 \pm 0.64$ and $0.95 \pm 0.84$ in placebo, respectively.

\section{Influence of FHE as monitored by MRS questionnaire}

Deviations in MRS scores were primarily used for evaluating the influence of supplementation at baseline (day $0)$ and day 42. There was a significant $(P \leq 0.05)$
Table 2 Baseline demographic characteristics of study participants

\begin{tabular}{|c|c|c|}
\hline Characteristics & $\begin{array}{l}\text { Placebo } \\
(n=22)\end{array}$ & $\begin{array}{l}\text { FHE } \\
(n=23)\end{array}$ \\
\hline Age (years) & $42.85 \pm 4.2$ & $41.10 \pm 3.7$ \\
\hline Weight (kg) & $62.3 \pm 4.2$ & $64.8 \pm 4.5$ \\
\hline BMI $\left(\mathrm{kg} / \mathrm{m}^{2}\right)$ & $23.7 \pm 1.5$ & $24.2 \pm 1.85$ \\
\hline Education & $\mathrm{n}, \%$ & $\mathrm{n}, \%$ \\
\hline Below high school & $6(25)$ & $5(22.7)$ \\
\hline High school and above & $16(75)$ & $18(77.2)$ \\
\hline \multicolumn{3}{|l|}{ Occupation } \\
\hline Employed & $17(85)$ & $16(72.7)$ \\
\hline Home-maker & $5(10)$ & $4(13.6)$ \\
\hline \multicolumn{3}{|l|}{ Marital status } \\
\hline Married & $15(68)$ & $14(61)$ \\
\hline Divorced & $1(5)$ & $3(13)$ \\
\hline Widow & $6(27)$ & $6(26)$ \\
\hline \multicolumn{3}{|l|}{ Residence } \\
\hline Urban & $16(72)$ & $19(83)$ \\
\hline Rural & $6(27)$ & $4(17)$ \\
\hline \multicolumn{3}{|l|}{ Exercise } \\
\hline Never & $12(54)$ & $14(61)$ \\
\hline Often & $4(18)$ & $5(22)$ \\
\hline Daily & $5(23)$ & $4(17)$ \\
\hline \multicolumn{3}{|l|}{ MRS } \\
\hline Total score & $2.27 \pm 1.27$ & $2.26 \pm 1.28$ \\
\hline Psychosocial score & $0.86 \pm 0.64$ & $0.87 \pm 0.81$ \\
\hline Somatic score & $0.45 \pm 0.59$ & $0.47 \pm 0.73$ \\
\hline Urogenital score & $0.95 \pm 0.84$ & $0.91 \pm 0.84$ \\
\hline
\end{tabular}

BMI- Body mass index, MRS- Menopause rating scale. Values are expressed as mean $\pm \mathrm{SD}$

improvement in the total MRS scores among FHE group (40.38\%) as compared to placebo (16\%) during the 42 days of study period. Somatic, psychological and urogenital symptoms scores showed 36.3, 35.0, and 47.6\% reduction in FHE group, while the placebo showed 10.0, 15.7 , and $33.3 \%$ improvements by the end of the study period. Further analysis of the individual symptom scores showed a significant reduction in the sexual problems (41.67\%) in FHE group when compared to placebo $(18.18 \%)$. The irritability scores were decreased by $40 \%$ in FHE group and $20.2 \%$ in placebo as shown in Fig. 3.

\section{Effect of FHE on hormone balance}

There was a significant increase in the levels of hormones after FHE supplementation. An increase in estradiol $(P=0.04)$, total testosterones $(P=0.012)$, and free testosterone $(P=0.025)$ were observed in the FHE group compared to placebo (Fig. 4). There were non-significant 


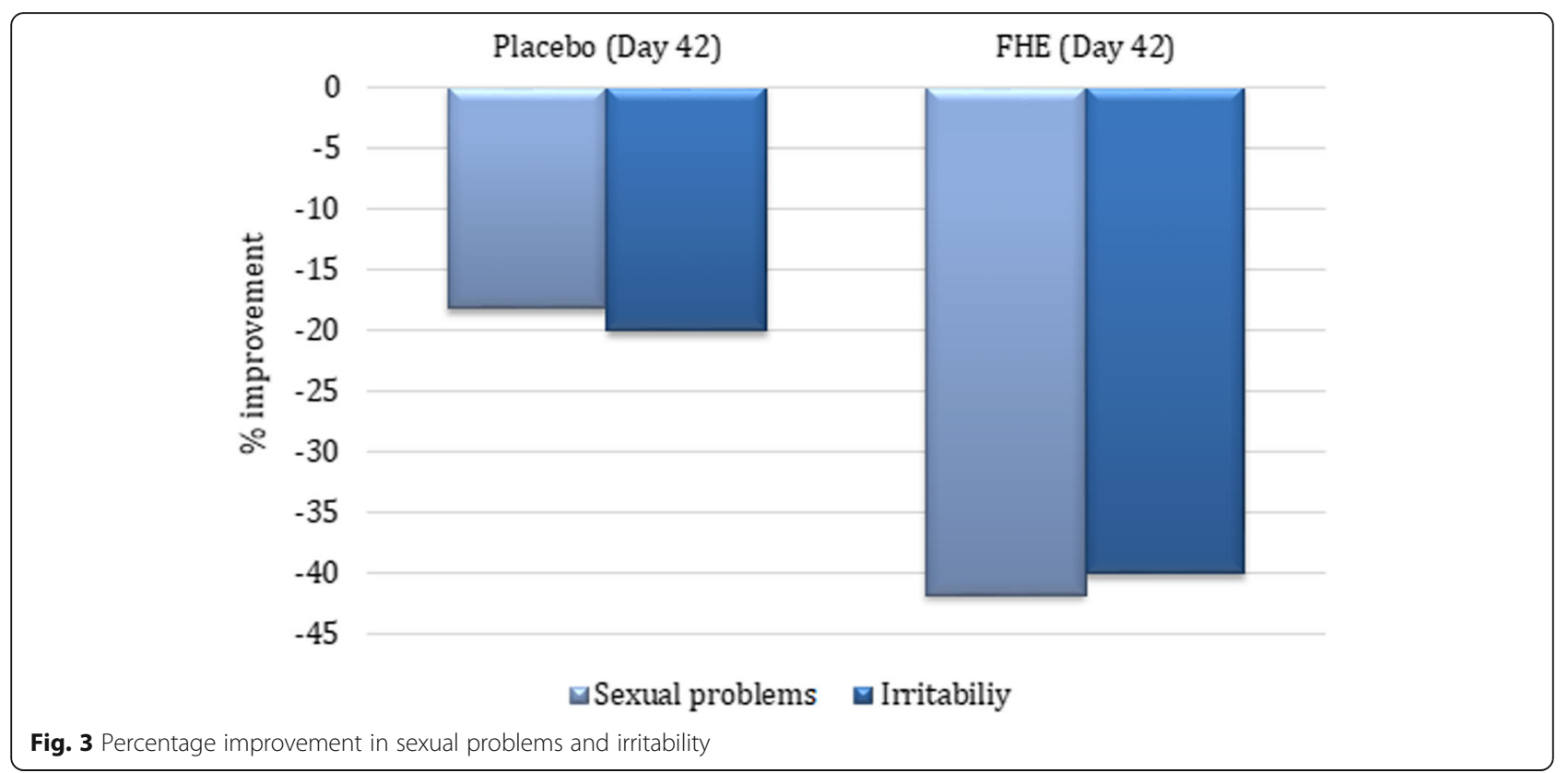

changes in the levels of progesterone $(P=0.174)$ and FSH $(P=0.879)$ in FHE group when compared to placebo and the intergroup comparison also revealed no significant changes (Table 3). Individual analysis of hormone concentrations revealed that only 18 participants out of 24 in the FHE group had showed an increase in estradiol level. The average percentage increase was $21 \%$, in which only seven participants showed above $10 \%$ increase in estradiol. In the case of testosterone, the average increase in total testosterone levels was $20 \%$. The increase was below $10 \%$ among participants who reported total testosterone value above $30 \mathrm{ng} / \mathrm{dL}$. Similarly, free testosterone levels showed an average of $24 \%$ increase, but the participants with free testosterone levels greater than $30 \mathrm{pg} / \mathrm{dL}$ had less than $10 \%$ increase (data not shown).

\section{Safety and tolerance of FHE supplementation}

During the study period, FHE was well tolerated without any adverse events. The assessment of hematological and biochemical parameters showed no significant changes in the baseline values (Table 4).

\section{Discussion}

Hormonal changes occur as women ages through menstrual cycles and menopausal phases as depicted in Fig. 1. The decline in androgen levels normally starts long before menopause; specifically from the perimenopausal age of around 47.5 years [22-24]. By the mid-30s or 40s, the normal activities of ovaries reduce and the process of ovulation becomes irregular [25]. In the perimenopause period, the levels of estradiol and progesterone decreases and in menopause, ovary can no longer release ova, and LH as well as FSH increase in the absence of ovarian estrogen feedback [2]. Estradiol and progesterone modulate sexual desire in women and the gradual and age-related cessation of ovarian function associated with natural menopause decreases the levels of these steroidal hormones and hence contribute towards the diminished sexual desire. This is a general observation among a significant portion of postmenopausal women [26].

The present study following a purposive sampling plan to select healthy women having some degree of sexual issues and irritability problems as reflected in the MRS scores, demonstrated a significant increase in estradiol and testosterone levels with a significant reduction in sexual issues and irritability scores when supplemented with FHE for 42 days at $250 \mathrm{mg} \times 2 /$ day. About $81 \%$ of participants in placebo and $88 \%$ in FHE group reported scores between one and four for sexual problems and irritability, indicating mild to medium issues with regard to sexual functioning. However, the participants did not report to have any notable vasomotor symptoms at the time of enrolment. Upon hormonal analysis, it was found that these women had relatively low levels of estrogen and testosterone though within the reference range.

Estradiol and testosterone are the major hormones that have been implicated for modulating women's sexual desire and functions [26]. These hormones activate the Hypothalamic-Pituitary-Gonadal (HPG) axis by binding with estrogen receptors and the activation of HPG axis is necessary for fertility [27, 28]. Decrease in serum estrogen causes a decrease in clitoral intracavernosal, vaginal, and urethral blood flow, due to diffuse 
$\mathbf{a}$

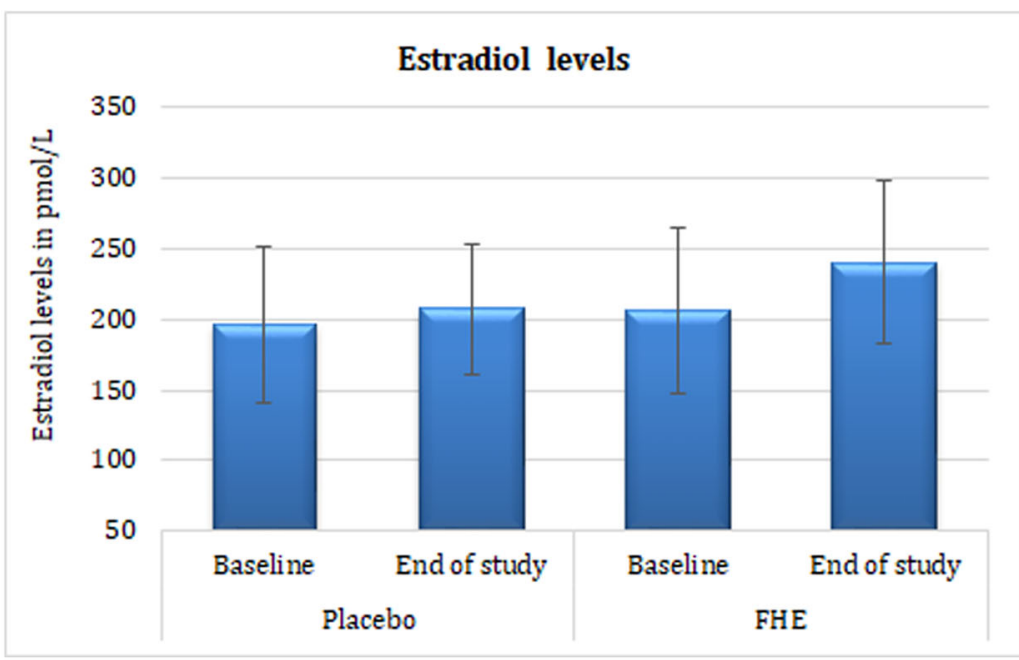

b

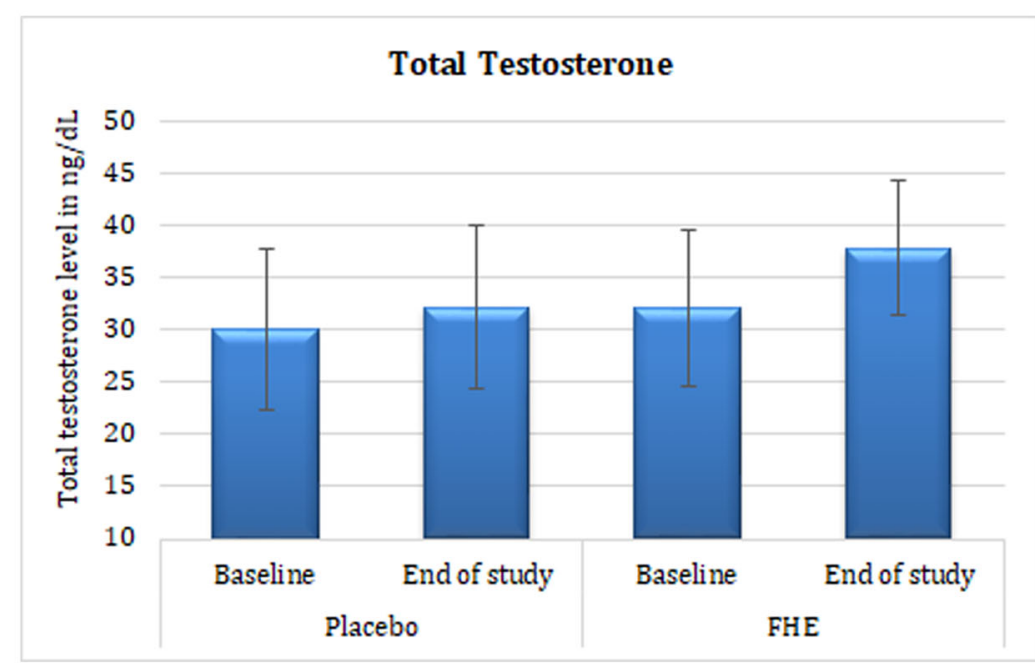

c

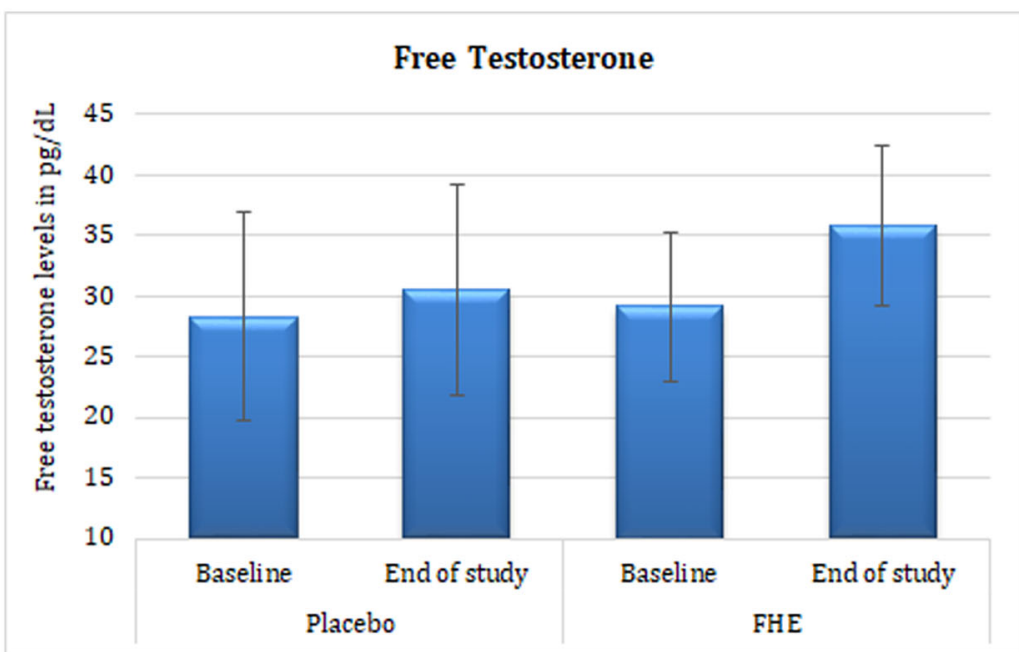

Fig. 4 Changes in the levels of (a) Estradiol (b) Total testosterone and (c) Free testosterone in FHE and placebo group at baseline and day 42 
Table 3 Hormone levels of placebo and FHE groups

\begin{tabular}{|c|c|c|c|c|c|}
\hline \multirow[t]{2}{*}{ Parameter } & \multicolumn{2}{|l|}{ Placebo } & \multicolumn{2}{|c|}{ FHE supplemented group } & \multirow[t]{2}{*}{$P$-value } \\
\hline & Baseline & End of Study & Baseline & End of Study & \\
\hline Estradiol (pmol/L) & $196.8 \pm 55.4$ & $207.1 \pm 45.9$ & $206.7 \pm 58.4$ & $240.3 \pm 57.9^{\#}$ & 0.040 \\
\hline Progesterone (nmol/L) & $2.47 \pm 0.92$ & $2.59 \pm 0.82$ & $2.61 \pm 0.70$ & $2.9 \pm 0.58$ & 0.174 \\
\hline Follicle stimulating hormone (IU/L) & $13.86 \pm 4.54$ & $13.15 \pm 4.47$ & $14.36 \pm 5.69$ & $12.97 \pm 5.89$ & 0.879 \\
\hline Total testosterone (ng/dL) & $30.02 \pm 7.65$ & $32.14 \pm 7.79$ & $31.94 \pm 7.47$ & $37.75 \pm 9.29^{\#}$ & 0.012 \\
\hline Free testosterone (pg/dL) & $28.25 \pm 8.59$ & $30.49 \pm 8.72$ & $29.11 \pm 6.09$ & $35.8 \pm 6.7^{\#}$ & 0.025 \\
\hline
\end{tabular}

Hormone levels of placebo and FHE groups at baseline vs end of study. A $2 \times 2$ repeated measures (RM) analysis of variance were performed with Bonferroni post hoc corrections. Values are expressed as Mean \pm SD. ${ }^{\#}$ indicate baseline vs end of study at $P \leq 0.05$

clitoral brosis, thinned vaginal epithelial layers, and decreased vaginal submucosal vasculature $[29,30]$. In our study, the level of estradiol was significantly increased in FHE group and no significant change was observed in placebo group at the end of the study (Table 3). This has further correlated with the results of MRS scores, especially in the percentage improvement in sexual problems and irritability scores (Fig. 3). There was no significant change in the hormone levels or MRS scores in placebo.

The observation that the supplementation of FHE increased the estrogen and testosterone levels and significantly improved the quality of sexual functions and quality of life among participants who had issues at the baseline levels indicates the beneficial effect of FHE [31]. Earlier studies have also reported significant enhancement in both estradiol and testosterones among menopausal and healthy population having low libido when supplemented with fenugreek extracts [14, 16-18]. Elevated concentrations of endogenous estrogen and hormonal therapy with estrogen have already been reported to ease the menopausal discomforts [32]. However, the enhancement in estradiol and testosterone among participants with normal baseline levels were not significant $(P>0.05)$, indicating relatively weak estrogenic activity for FHE. Phytoestrogens are generally shown to possess weak binding with receptors [33]. So, under normal healthy conditions when there is enough natural estrogen in the body, the receptors available for binding with phytoestrogens will be limited. But, in the case of insufficient estrogen levels, phytoestrogens may bind to the receptors and support to ameliorate the symptoms associated with low estrogen levels. Phytoestrogens can also affect estrogen levels in ovarian tissue by interfering with estrogensynthesizing and metabolic enzymes such as aromatase and estrogen receptors signalling pathways [34].

Androgens play an important role in healthy female sexual function, especially in stimulating sexual interest and maintaining desire [35]. Testosterone initiates sexual activities and proliferates sexual desire and behaviour. In addition, testosterone is essential in modulating clitoral and vaginal physiology to facilitate genital lubrication, sensation, and engorgement [36]. The greatest decline in circulating testosterone occurs during the late reproductive years [37]. Lack of testosterone has been reported to contribute to low libido and reduced sexual pleasure characterised by low sexual motivation, fatigue, distress, and overall reduction in the sense of well-being [33-35].

Oral and transdermal testosterone delivery has been shown to improve self-reported sexual satisfaction among premenopausal and postmenopausal women with low libido [36, 37]. A recent report has also evidenced the use of testosterone therapy to improve components of female sexual dysfunction [38]. Thus, the baseline sexual issues reflected by the MRS score in the present study can be dedicated to the lower normal range of testosterone. The increased total testosterone and free testosterone level after FHE supplementation might have also resulted in the improved sexual functions and libido.

Testosterone levels decline with age prior to menopause $[39,40]$. There is $~ 50 \%$ fall in both total and free testosterones between the ages of 20 and 40-45, with only a very slight fall in circulating concentrations thereafter (Fig. 1). In a study on 149 healthy premenopausal women having no low libido complains and regular cycles, it was shown that a statistically significant decline for each of free testosterone, dehydroepiandrosterone sulfate (DHEAS), androstenedione and Dihydrotestosterone (DHT) occur with aging [41]. Testosterone can be converted to either DHT or estradiol by the enzymes $5 \alpha$-reductase and aromatase, respectively [42]. Dehydroepiandrosterone (DHEA) is the principal precursor of both androstenedione and testosterone androgens and $50 \%$ of DHEA is produced in the adrenal glands and $20 \%$ from the ovaries; $30 \%$ is derived from DHEAS that circulates in the blood [43]. During post-menopause, up to $60 \%$ of DHEA tend to decline, resulting in hypoandrogenism which can affect the normal sexual response in women [44].

The molecular mechanism behind the beneficial effect of FHE can be mainly attributed to its protodioscin content, a furostanolic saponin molecule having a significant structural similarity with DHEA. It was shown that protodioscin can be converted to DHEA [45], which further 
Table 4 Hematological and biochemical parameters in FHE and placebo

\begin{tabular}{|c|c|c|c|c|}
\hline Parameters & Groups & Baseline & End of Study & $P$-value \\
\hline Hemoglobin (g/dL) & $\begin{array}{l}\text { Placebo } \\
\text { FHE }\end{array}$ & $\begin{array}{l}15.3 \pm 0.3 \\
14.1 \pm 0.4\end{array}$ & $\begin{array}{l}14.8 \pm 0.3 \\
14.5 \pm 0.4\end{array}$ & 0.075 \\
\hline Total leukocyte count (cells/cumm) & $\begin{array}{l}\text { Placebo } \\
\text { FHE }\end{array}$ & $\begin{array}{l}6072 \pm 304.5 \\
6195 \pm 318.1\end{array}$ & $\begin{array}{l}6178 \pm 321.5 \\
6305 \pm 345.2\end{array}$ & 0.549 \\
\hline Total RBC count (million/cumm) & $\begin{array}{l}\text { Placebo } \\
\text { FHE }\end{array}$ & $\begin{array}{l}4.3 \pm 0.12 \\
4.5 \pm 0.14\end{array}$ & $\begin{array}{l}4.6 \pm 0.11 \\
4.4 \pm 0.10\end{array}$ & 0.788 \\
\hline PC (lakhs/cumm) & $\begin{array}{l}\text { Placebo } \\
\text { FHE }\end{array}$ & $\begin{array}{l}2.5 \pm 0.32 \\
2.4 \pm 0.3\end{array}$ & $\begin{array}{l}2.3 \pm 0.28 \\
2.2 \pm 0.25\end{array}$ & 0.325 \\
\hline PCV (\%) & $\begin{array}{l}\text { Placebo } \\
\text { FHE }\end{array}$ & $\begin{array}{l}38.5 \pm 1.5 \\
34.3 \pm 1.2\end{array}$ & $\begin{array}{l}35.4 \pm 1.1 \\
32.3 \pm 1.2\end{array}$ & 0.333 \\
\hline $\mathrm{MCH}(\mathrm{pg})$ & $\begin{array}{l}\text { Placebo } \\
\text { FHE }\end{array}$ & $\begin{array}{l}30.7 \pm 1.4 \\
32.3 \pm 1.3\end{array}$ & $\begin{array}{l}32.9 \pm 1.5 \\
31.8 \pm 1.3\end{array}$ & 0.385 \\
\hline $\mathrm{MCHC}(\mathrm{g} / \mathrm{dL})$ & $\begin{array}{l}\text { Placebo } \\
\text { FHE }\end{array}$ & $\begin{array}{l}85.5 \pm 2.7 \\
87.2 \pm 2.5\end{array}$ & $\begin{array}{l}82.1 \pm 2.3 \\
85.3 \pm 2.4\end{array}$ & 0.323 \\
\hline $\mathrm{MCV}(\mathrm{fL})$ & $\begin{array}{l}\text { Placebo } \\
\text { FHE }\end{array}$ & $\begin{array}{l}92.7 \pm 2.5 \\
94.8 \pm 2.8\end{array}$ & $\begin{array}{l}95.1 \pm 2.3 \\
96.4 \pm 2.5\end{array}$ & 0.961 \\
\hline Neutrophils (\%) & $\begin{array}{l}\text { Placebo } \\
\text { FHE }\end{array}$ & $\begin{array}{l}52.7 \pm 3.1 \\
50.8 \pm 3.0\end{array}$ & $\begin{array}{l}55.1 \pm 4.0 \\
52.4 \pm 3.7\end{array}$ & 0.439 \\
\hline Lymphocytes (\%) & $\begin{array}{l}\text { Placebo } \\
\text { FHE }\end{array}$ & $\begin{array}{l}40.7 \pm 2.0 \\
42.2 \pm 2.1\end{array}$ & $\begin{array}{l}38.4 \pm 2.2 \\
36.9 \pm 2.0\end{array}$ & 0.662 \\
\hline Eosinophil's (\%) & $\begin{array}{l}\text { Placebo } \\
\text { FHE }\end{array}$ & $\begin{array}{l}4.2 \pm 0.65 \\
4.0 \pm 0.72\end{array}$ & $\begin{array}{l}4.1 \pm 0.62 \\
3.8 \pm 0.55\end{array}$ & 0.795 \\
\hline Monocytes (\%) & $\begin{array}{l}\text { Placebo } \\
\text { FHE }\end{array}$ & $\begin{array}{l}3.2 \pm 0.65 \\
3.1 \pm 0.62\end{array}$ & $\begin{array}{l}3.5 \pm 0.52 \\
3.3 \pm 0.54\end{array}$ & 0.980 \\
\hline $\operatorname{ESR}(\mathrm{mm} / \mathrm{hr})$ & $\begin{array}{l}\text { Placebo } \\
\text { FHE }\end{array}$ & $\begin{array}{l}10.4 \pm 1.0 \\
10.6 \pm 1.2\end{array}$ & $\begin{array}{l}8.4 \pm 0.92 \\
8.8 \pm 1.1\end{array}$ & 0.342 \\
\hline Triglycerides & $\begin{array}{l}\text { Placebo } \\
\text { FHE }\end{array}$ & $\begin{array}{l}126.3 \pm 4.5 \\
129.5 \pm 4.8\end{array}$ & $\begin{array}{l}136.2 \pm 5.2 \\
132.5 \pm 5.4\end{array}$ & 0.773 \\
\hline Total Cholesterol & $\begin{array}{l}\text { Placebo } \\
\text { FHE }\end{array}$ & $\begin{array}{l}192.4 \pm 7.5 \\
189.7 \pm 7.2\end{array}$ & $\begin{array}{l}185.7 \pm 6.5 \\
182.2 \pm 6.2\end{array}$ & 0.642 \\
\hline HDL Cholesterol & $\begin{array}{l}\text { Placebo } \\
\text { FHE }\end{array}$ & $\begin{array}{l}40.2 \pm 2.2 \\
43.5 \pm 2.5\end{array}$ & $\begin{array}{l}42.7 \pm 2.5 \\
45.5 \pm 2.5\end{array}$ & 0.698 \\
\hline LDL Cholesterol & $\begin{array}{l}\text { Placebo } \\
\text { FHE }\end{array}$ & $\begin{array}{l}152.8 \pm 4.2 \\
148.7 \pm 4.0\end{array}$ & $\begin{array}{l}158.2 \pm 4.2 \\
152.7 \pm 4.8\end{array}$ & 0.380 \\
\hline VLDL Cholesterol & $\begin{array}{l}\text { Placebo } \\
\text { FHE }\end{array}$ & $\begin{array}{l}28.7 \pm 7.2 \\
26.1 \pm 8.1\end{array}$ & $\begin{array}{l}25.7 \pm 6.8 \\
27.2 \pm 7.7\end{array}$ & 0.298 \\
\hline SGOT (U/L) & $\begin{array}{l}\text { Placebo } \\
\text { FHE }\end{array}$ & $\begin{array}{l}23.1 \pm 4.2 \\
26.7 \pm 4.8\end{array}$ & $\begin{array}{l}25.4 \pm 4.9 \\
27.3 \pm 5.2\end{array}$ & 0.822 \\
\hline SGPT (U/L) & $\begin{array}{l}\text { Placebo } \\
\text { FHE }\end{array}$ & $\begin{array}{l}35.2 \pm 7.2 \\
38.5 \pm 7.6\end{array}$ & $\begin{array}{l}32.7 \pm 6.7 \\
35.3 \pm 6.5\end{array}$ & 0.717 \\
\hline Alkaline phosphatase & $\begin{array}{l}\text { Placebo } \\
\text { FHE }\end{array}$ & $\begin{array}{l}55.7 \pm 7.0 \\
62.8 \pm 7.8\end{array}$ & $\begin{array}{l}52.7 \pm 7.2 \\
55.3 \pm 7.4\end{array}$ & 0.353 \\
\hline
\end{tabular}

RBC- Red blood cells, PC- Platelet count, PCV- Packed cell volume, MCH- Mean corpuscular hemoglobin, MCHC- Mean corpuscular hemoglobin concentration, MCV- Mean corpuscular volume, ESR- Erythrocyte sedimentation rate, HDL- High-density lipoprotein, LDL- Low-density lipoprotein, VLDL- Very low-density lipoprotein, SGOT- Serum glutamate oxaloacetate transferase, SGPT- Serum glutamate pyruvate transferase. A general linear model with adjustments for baseline values were used to predict marginal means $(95 \% \mathrm{Cl})$ for each outcome variable. Values are expressed as mean $\pm \mathrm{SD}$. $P \leq 0.05$ considered as statistically significant with baseline

gets converted to testosterone and estradiol. Aromatase is involved in the conversion of testosterone to estradiol [46]. Zhou et al. have reported a significant increase of $17 \beta$-Hydroxy Steroid Dehydrogenase (17 $\beta-H S D), 3 \beta-H y$ droxy Steroid Dehydrogenase (3 $\beta-H S D)$ and aromatase mRNA levels when female rats were treated with DHEA [47]. The enzymes $17 \beta-H S D$ and $3 \beta-H S D$ are important in the synthesis of steroid hormones such as testosterone and estradiol which are involved to activate the Hypothalamic-Pituitary-Gonadal (HPG) axis by binding with estrogen receptors $[27,28]$. Trigonelline, yet another major component in FHE has also been proven to enhance the estrogen level by some unknown mechanisms [48]. 
In women, abnormally high concentration of testosterone has been associated with polycystic ovary syndrome (PCOS) and ovarian cancers [49]. Serum levels of testosterone has been suspected in the etiology of breast cancer of postmenopausal women [50]. Most testosterone values in PCOS will be $\leq 150 \mathrm{ng} / \mathrm{dL}(\leq 5.2 \mathrm{nmol} / \mathrm{L})$ [49], and in ovarian or adrenal tumour, it is shown to be of $\geq 200 \mathrm{ng} / \mathrm{dL}$ ( $\geq 6.9 \mathrm{nmol} / \mathrm{L}$ ). The enzyme like ovarian aromatase activity is lower under PCOS conditions [51]. This may limit the conversion of testosterone to estradiol as well. So, the consumption of fenugreek extracts by women having PCOS conditions have to be careful, though earlier study has reported the beneficial effects of fenugreek under PCOS condition [52]. However, the role of phytoestrogens is ambiguous and they bind weakly to estrogen receptors and can either produce or inhibit estrogen effects [53]. In the present study, no overproduction of hormones has been observed with FHE intake, probably due to the active feedback mechanism in healthy women, which warrants further study on healthy participants. Since, estradiol is known to increase the concentration of serotonin and modulate its action, the effects of FHE on serotonin pathways also can be investigated to check the beneficial effects of FHE in menopausal discomforts and sexual issues.

\section{Conclusions}

In summary, supplementation of FHE at $250 \mathrm{mg} \times 2$ per day for 42 days did not produce any side effects, adverse events or significant changes in both the haematological and biochemical parameters in young menstruating women. Further analysis indicated no detrimental effect on hormonal balance. The enhancement observed for estradiol and testosterone concentrations were within the safe reference range. The molecular mechanism of estrogenic effect can be attributed to the protodioscin content in FHE, since protodioscin can be converted to DHEA and further to testosterone and estradiol by the action of aromatase. The present study showed that FHE helps to maintain normal hormonal balance and offered a significant reduction in sexual problems and irritability scores among the participants.

\footnotetext{
Abbreviations

HPG: Hypothalamic-pituitary-gonadal; FSH: Follicle stimulating hormone; LH: Luteinizing hormone; NSAIDs: Non-steroid anti-inflammatory drugs; FHE: Fenugreek seed extract; MRS: Menopausal rating scale; LD 50 : Lethal dose; CONSORT: Consolidated standards of reporting trials; CTRI: Clinical trail registry of India; EDTA: Ethylenediamine tetraacetic acid; SGOT: Serum glutamate oxaloacetate transaminase; SGPT: Serum glutamate pyruvate transaminase; HDL: High-density lipoprotein cholesterol; LDL: Low-density lipoprotein cholesterol; VLDL: Very low-density lipoprotein cholesterol; FBS: Fasting blood sugar; BMI: Body mass index; PCOS: Polycystic ovary syndrome; DHEAS: Dehydroepiandrosterone sulfate;

DHT: Dihydrotestosterone; DHEA: Dehydroepiandrosterone; RBC: Red blood cells; PC: Platelet count; PCV: Packed cell volume; $\mathrm{MCH}$ : Mean corpuscular haemoglobin; MCHC: Mean corpuscular hemoglobin concentration; MCV: Mean corpuscular volume; ESR: Erythrocyte sedimentation rate
}

\section{Acknowledgements}

The authors thank Thyrocare, Bangalore, India for providing the laboratory services.

\section{Authors' contributions}

Aman Khanna: Investigation; Supervision. Jestin Thomas: Data curation; Formal analysis; Methodology; Project administration; Software; Validation; Writing-review \& editing. Febi John: Formal analysis; Writing-original draft: Writing-review \& editing. Balu Makiakel: Conceptualization; funding acquisition; Resources. Krishnakumar IM: Conceptualization; funding acquisition; Visualization; Writing review \& editing. The author(s) read and approved the final manuscript.

\section{Funding}

The study was financially supported by M/s Akay Natural Ingredients, Cochin, India as a part of the research program (Reg. No. AK/R\&D/NPP-05/2018) for the development of 'Spiceuticals' - the nutraceutical ingredients from spices. The funders have developed the formulation, conceived the idea, and prepared the manuscript; but had no role in the execution of the study, sample collection, analysis and interpretation of data.

\section{Availability of data and materials}

The dataset analysed in the present study are available from the corresponding author on reasonable request.

\section{Declaration}

Ethics approval and consent to participate

The study was in accordance with the clinical research guidelines of Government of India following the protocol evaluated and was registered in the clinical trial registry of India at http:/ctri.nic.in (CTRI/2018/09/01 5614 dated 05/09/2018).

\section{Consent for publication}

Not applicable.

\section{Competing interests}

The author(s) declared the following potential conflicts of interest with respect to the research, authorship, and/or publication of this article. FHE used in the study is a patented extract of Akay Natural Ingredients, Cochin, India as FenuSMART'.

\section{Author details}

${ }^{1}$ Aman Hospital and Research Center, Vadodara, Gujarat, India. ${ }^{2}$ Leads Clinical Research and Bio Services Pvt. Ltd., Bangalore, India. ${ }^{3}$ R\&D Center, Akay Natural Ingredients Ltd., Cochin, India.

Received: 19 February 2021 Accepted: 17 June 2021

Published online: 13 July 2021

\section{References}

1. Acevedo-Rodriguez A, Kauffman AS, Cherrington BD, Borges CS, Roepke TA, Laconi M. Emerging insights into hypothalamic-pituitary-gonadal axis regulation and interaction with stress signalling. J Neuroendocrinol. 2018; 30(10):e12590. https://doi.org/10.1111/jne.12590.

2. Venkatesh KK, Cu-Uvin S. Anatomic and Hormonal Changes in the Female Reproductive Tract Immune Environment during the Life Cycle: Implications for HIV/STI Prevention Research. Am J Reprod Immunol. 2014;71:495-504. https://doi.org/10.1111/aji.12247.

3. Marquardt RM, Kim TH, Shin JH, Jeong JW. Progesterone and estrogen signaling in the endometrium: what goes wrong in endometriosis? Int J Mol Sci. 2019;20(15). https://doi.org/10.3390/ijms20153822.

4. Sex Hormones Ageing Levels Testosterone Males Stock Illustration 1362318992, (n.d.)

5. Dawood MY. Primary dysmenorrhea: advances in pathogenesis and management. Obstet Gynecol. 2006;108(2):428-41. https://doi.org/10.1097/ 01.AOG.0000230214.26638.0c

6. Ryan SA. The treatment of dysmenorrhea. Pediatr Clin N Am. 2017:64(2): 331-42. https://doi.org/10.1016/j.pcl.2016.11.004.

7. Barcikowska Z, Wójcik-Bilkiewicz K, Sobierajska-Rek A, Grzybowska ME, Wąż P, Zorena K. Dysmenorrhea and associated factors among polish women: a 
cross-sectional study. Pain Res Manag. 2020;2020:1-10. https://doi.org/10.11 55/2020/6161536.

8. Oladosu FA, Tu FF, Hellman KM. Nonsteroidal antiinflammatory drug resistance in dysmenorrhea: epidemiology, causes, and treatment. Am J Obstet Gynecol. 2018;218(4):390-400. https://doi.org/10.1016/j.ajog.2017.08.108.

9. Gava G, Orsili I, Alvisi S, Mancini I, Seracchioli R, Meriggiola MC. Cognition, mood and sleep in menopausal transition: the role of menopause hormone therapy. Med. 2019;55(10). https://doi.org/10.3390/medicina55100668.

10. Ibrahim ZM, Sayed Ahmed WA, El-Hamid SA. Prevalence of menopausal related symptoms and their impact on quality of life among Egyptian women. Clin Exp Obstet Gynecol. 2015;42(2):161-7. https://pubmed.ncbi. nlm.nih.gov/26054110/.

11. Johnson A, Roberts L, Elkins G. Complementary and alternative medicine for menopause. J Evidence-Based Integr Med. 2019;24:1-14. https://doi.org/1 $0.1177 / 2515690 \times 19829380$

12. Younesy S, Amiraliakbari S, Esmaeili S, Alavimajd H, Nouraei S. Effects of fenugreek seed on the severity and systemic symptoms of dysmenorrhea. J Reprod Infertil. 2014; 15: 41-48. /pmc/articles/PMC3955423/?report=abstract.

13. Yadav UCS, Baquer NZ. Pharmacological effects of Trigonella foenumgraecum L. in health and disease. Pharm Biol. 2014;52(2):243-54. https://doi. org/10.3109/13880209.2013.826247.

14. Rao A, Steels E, Beccaria G, Inder WJ, Vitetta L. Influence of a specialized Trigonella foenum-graecum seed extract (Libifem), on testosterone, estradiol and sexual function in healthy menstruating women, a randomised placebo controlled study. Phyther Res. 2015;29(8):1123-30. https://doi.org/10.1002/ ptr.5355.

15. Tabares FP, Jaramillo JVB, Ruiz-Cortés ZT. Pharmacological overview of Galactogogues. Vet Med Int. 2014;2014:1-20. https://doi.org/10.1155/2014/ 602894.

16. Thomas JV, Rao J, John F, Begum S, Maliakel B, Krishnakumar IM, et al. Phytoestrogenic effect of fenugreek seed extract helps in ameliorating the leg pain and vasomotor symptoms in postmenopausal women: A randomized, double-blinded, placebo-controlled study. Pharma Nutrition. 2020;14:100209. https://doi.org/10.1016/j.phanu.2020.100209.

17. Khanna A, John F, Das S, Thomas J, Rao J, Maliakel B, et al. Efficacy of a novel extract of fenugreek seeds in alleviating vasomotor symptoms and depression in perimenopausal women: a randomized, double-blinded, placebo-controlled study. J Food Biochem. 2020;44(12):e13507. https://doi. org/10.1111/jfbc.13507.

18. Begum SS, Jayalakshmi HK, Vidyavathi HG, Gopakumar G, Abin I, Balu M, et al. A novel extract of fenugreek husk (FenuSMART ${ }^{\mathrm{m}}$ ) alleviates postmenopausal symptoms and helps to establish the hormonal balance: a randomized, double-blind. Placebo-Controlled Study. 2016;30(11):1775-84. https://doi.org/10.1002/ptr.5680.

19. USP, General Chapter Articles of Botanical Origin/USP-NF, United States Pharmacopeial Conv. Rockville, MD. 2014.

20. Sureshkumar D, Begum S, Johannah NM, Maliakel B, Krishnakumar IM. Toxicological evaluation of a saponin-rich standardized extract of fenugreek seeds (FenuSMART $\circledast$ ): acute, sub-chronic and genotoxicity studies. Toxicol Reports. 2018;5:1060-8. https://doi.org/10.1016/j.toxrep.2018.10.008.

21. Heinemann K, Ruebig A, Potthoff P, Schneider HPG, Strelow F, Heinemann LAJ, et al. The menopause rating scale (MRS) scale: a methodological review. Health Qual Life Outcomes. 2004;2(1):45. https://doi.org/10.1186/14 77-7525-2-45

22. Gold EB. The timing of the age at which natural menopause occurs. Obstet Gynecol Clin N Am. 2011;38(3):425-40. https://doi.org/10.1016/j.ogc.2011.05.002.

23. Woodard T, Diamond M. Contribution of imaging to our understanding of sexual function and dysfunction. Adv Psychosom Med. 2008;29:150-68. https://doi.org/10.1159/000126629.

24. Arnow BA, Millheiser L, Garrett A, Lake Polan M, Glover GH, Hill KR, et al. Women with hypoactive sexual desire disorder compared to normal females: a functional magnetic resonance imaging study. Neuroscience. 2009;158(2):484-502. https://doi.org/10.1016/j.neuroscience.2008.09.044.

25. Age and Fertility A Guide for Patients: Patient Information Series. 2012

26. Cappelletti M, Wallen K. Increasing women's sexual desire: The comparative effectiveness of estrogens and androgens. Horm Behav. 2016;78:178-93. https://doi.org/10.1016/j.yhbeh.2015.11.003.

27. Wintermantel TM, Campbell RE, Porteous R, Bock D, Gröne HJ, Todman MG, et al. Definition of estrogen receptor pathway critical for estrogen positive feedback to gonadotropin-releasing hormone neurons and fertility. Neuron. 2006;52(2):271-80. https://doi.org/10.1016/j.neuron.2006.07.023.
28. Dimitraki M, Koutlaki N, Gioka T, Messini Cl, Dafopoulos K, Anifandis G, et al. Attenuation of the oestrogen positive feedback mechanism with the age in postmenopausal women. Clin Endocrinol (Oxf). 2015;83:377-83. https://doi. org/10.1111/cen.12735.

29. Berman JR, Berman LA, Lin H, Goldstein I. Female sexual dysfunction: epidemiology, physiology, evaluation, and treatment. In: Mulcahy JJ, editor. Male sexual function. Current Clinical Urology. Totowa: Humana Press; 2001. p. 123-39. https://doi.org/10.1007/978-1-59259-098-8_7.

30. Dündar M, Koçak A, Erkuş M, Celasun B. The effect of estrogen-replacement therapy on clitoral-cavernosal tissue in oophorectomized rats: a histoquantitative study by image analyzer. Urol Res. 2001;29:317-20. https://doi. org/10.1007/s002400100202.

31. Patisaul HB, Jefferson W. The pros and cons of phytoestrogens. Front Neuroendocrinol. 2010;31 (4):400-19. https://doi.org/10.1016/j.yfrne.2010.03. 003.

32. Key TJ, Verkasalo PK, Banks E. Epidemiology of breast cancer. Lancet Oncol. 2001;2(3):133-40. https://doi.org/10.1016/S1470-2045(00)00254-0.

33. Baber R. Phytoestrogens and post reproductive health. Maturitas. 2010;66(4): 344-9. https://doi.org/10.1016/j.maturitas.2010.03.023.

34. Van Duursen MBM. Modulation of estrogen synthesis and metabolism by phytoestrogens: In vitro and the implications for women's health. Toxicol Res (Camb). 2017;6(6):772-94. https://doi.org/10.1039/c7t×00184c.

35. Bolour S, Braunstein G. Testosterone therapy in women: a review. Int J Impot Res. 2005;17(5):399-408. https://doi.org/10.1038/s.j.jir.3901334.

36. Nappi RE, Detaddei S, Ferdeghini F, Brundu B, Sommacal A, Polatti F. Role of testosterone in feminine sexuality. J Endocrinol Investig. 2003;26(3 Suppl): 97-101 https://pubmed.ncbi.nlm.nih.gov/12834031/.

37. Davison SL, Bell R, Donath S, Montalto JG, Davis SR. Androgen levels in adult females: changes with age, menopause, and oophorectomy. J Clin Endocrinol Metab. 2005;90(7):3847-53. https://doi.org/10.1210/jc.2005-0212.

38. Khera M. Testosterone therapy for female sexual dysfunction. Sex Med Rev. 2015;3(3):137-44. https://doi.org/10.1002/smr.53.

39. Simon JA. Estrogen replacement therapy: Effects on the endogenous androgen milieu. Fertil Steril. 2002:77-82. https://doi.org/10.1016/s0015-0282 (02)02986-2 Elsevier Inc.

40. Riley A, Riley E. Controlled studies on women presenting with sexual drive disorder: I. Endocrine status. J Sex Marital Ther. 2000;26(3):269-83. https:// doi.org/10.1080/00926230050084669

41. Davis SR. When to suspect androgen deficiency other than at menopause. In: Fertil Steril Elsevier Inc. 2002;77(4 supply 4):68-71. https://doi.org/10.101 6/s0015-0282(02)02977-1

42. Gonzales RJ, Ansar S, Duckles SP, Krause DN. Androgenic/estrogenic balance in the male rat cerebral circulation: metabolic enzymes and sex steroid receptors. J Cereb Blood Flow Metab. 2007;27(11):1841-52. https://doi.org/1 0.1038/sj.jcbfm.9600483.

43. Rivera-Woll LM, Papalia M, Davis SR, Burger HG. Androgen insufficiency in women: diagnostic and therapeutic implications. Hum Reprod Update. 2004;10(5):421-32. https://doi.org/10.1093/humupd/dmh037.

44. Helena Proni Fonseca JMA, Scapinelli A, Aoki T. Androgen Deficiency in women. Eur J Endocrinol. 2010;56:579-82. https://doi.org/10.1530/eje.1.0.

45. Adimoelja A. Phytochemicals and the breakthrough of traditional herbs in the management of sexual dysfunctions. Int J Androl. 2000;23(Suppl 2):82-4. https://doi.org/10.1046/j.1365-2605.2000.00020.x.

46. Payne AH, Hales DB. Overview of steroidogenic enzymes in the pathway from cholesterol to active steroid hormones. Endocr Rev. 2004;25:947-70. https://doi.org/10.1210/er.2003-0030.

47. Zhou Y, Kang J, Chen D, Han N, Ma H. Ample evidence: Dehydroepiandrosterone (DHEA) conversion into activated steroid hormones occurs in adrenal and ovary in female rat. PLoS One. 2015;10(5): e0124511. https://doi.org/10.1371/journal.pone.0124511.

48. Allred KF, Yackley KM, Vanamala J, Allred CD. Trigonelline is a novel phytoestrogen in coffee beans. J Nutr. 2009;139(10):1833-8. https://doi.org/1 0.3945/jn.109.108001.

49. Sheehan MT. Polycystic ovarian syndrome: diagnosis and management. Clin Med Res. 2004;2(1):13-27. https://doi.org/10.3121/cmr.2.1.13.

50. Sowers MF, Beebe JL, McConnell D, Randolph J, Jannausch M. Testosterone concentrations in women aged 25-50 years: associations with lifestyle, body composition, and ovarian status. Oxford Acad Am J Epidemiol. 2001;153(3): 256-64.

51. Chen J, Shen S, Tan Y, Xia D, Xia Y, Cao Y, et al. The correlation of aromatase activity and obesity in women with or without polycystic ovary 
syndrome. J Ovarian Res. 2015;8(1):11. https://doi.org/10.1186/s13048-0150139-1.

52. Swaroop A, Jaipuriar AS, Gupta SK, Bagchi M, Kumar P, Preuss HG, et al. Efficacy of a novel fenugreek seed extract (Trigonella foenum-graecum, furocyst $^{T^{T M}}$ ) in polycystic ovary syndrome (PCOS). Int J Med Sci. 2015;12(10): 825-31. https://doi.org/10.7150/ijms.13024.

53. Regina G. Ziegler. Phytoestrogens and breast cancer. Am J Clin Nutr. 2004; 79(2):183-4. https://doi.org/10.1093/ajcn/79.2.183.

\section{Publisher's Note}

Springer Nature remains neutral with regard to jurisdictional claims in published maps and institutional affiliations.

\section{Submit your manuscript to a SpringerOpen ${ }^{\circ}$ journal and benefit from:}

- Convenient online submission

- Rigorous peer review

- Open access: articles freely available online

High visibility within the field

- Retaining the copyright to your article

Submit your next manuscript at $\boldsymbol{\nabla}$ springeropen.com 